\title{
The Relationship Between Arm Muscle Strength and Grip Strength on Throwing Distance
}

\author{
Gustiana Mega Anggita ${ }^{1}$, Hari Amirullah Rachman ${ }^{2}$, Mohammad Arif $\mathrm{Ali}^{3}$, Sugiarto $^{4}$, Siti \\ Baitul Mukarromah ${ }^{5}$ \\ \{mega.anggita@mail.unnes.ac.id ${ }^{1}$, hari.rachman68@gmail.com ${ }^{2}$, hiarifalikhan@mail.unnes.ac.id ${ }^{3}$ \} \\ Universitas Negeri Semarang, Semarang, Indonesia ${ }^{1,3}$ \\ Yogyakarta State University, Yogyakarta, Indonesia ${ }^{2}$
}

\begin{abstract}
The purpose of this study was to determine the relationship between arm muscle strength and grip strength on the throwing distance of female softball athletes. This research is a correlational study using a survey method. The sample in this study was female softball athletes in Semarang City obtained by the total sampling method. Data collection techniques using tests and measurements. The data analysis technique used correlational analysis. There is a relationship between arm muscle strength and the throwing distance of the female softball athletes in Semarang city with a correlation value of 0.893 with a significance value of 0.000 . There is no relationship between the grip strength and the throwing distance for female softball athletes in Semarang city with a significance value of $0.448>0.05$. Arm muscle strength contributes to the throwing distance, while grip strength does not contribute to the throwing distance in female softball athletes in Semarang.
\end{abstract}

Keywords: Throwing performance, softball skill, elite athlete.

\section{Introduction}

Softball is a type of sport played by two teams of 9 people each team for seven innings or up to an agreed time limit consisting of attacking (hitting) and defending [1], [2]. Softball is a fun and exciting sport, providing significant health benefits such as increased physical fitness, including strength, agility, and upper and lower body coordination. Additionally, important social skills can be learned by interacting with coaches and teammates [3]. Softball is a development of baseball [4]. Softball is a physically demanding sport consisting of several specializations that require different skills and types of abilities.

Softball requires excellent hand-eye coordination, upper limb strength, handgrip strength, and coordinated movement of the hips, shoulders, arms, and wrists [5]. The ability to be in the physical condition is one factor that determines performance in softball [6]. The ability to be in the physical condition is one factor that determines performance in softball. Some of the basic techniques that need to be mastered from this softball game are 1) throwing, 2) hitting. 3) Catching, 4) baserunning, 5) sliding [7]. Throwing is one of the most important defensive skills in softball. Overhead throwing skills depend on the flexibility and mobility of the shoulder joint [8]. Throwing and catching skills are essential techniques when the team is defensive in a softball match. Throwing is a crucial technique or skill that plays a vital role in softball performance. Softball games have three general throwing techniques: overhead throw, sidearm throw, and underhand throw. The overhead throw technique is the technique most often used. 
To make a good overhead throw, the athlete must have good flexibility, muscle strength, coordination, muscle synchronization, and neuromuscular efficiency [9], [10].

The throwing technique in softball is an explosive action that requires muscle power. Power is a component of speed and strength. Softball players need muscle strength to perform the throwing technique [9]. This throwing skill is one of the determining factors for performance in softball games. One of the factors in throwing abilities is the arm muscles strenght and the grip's strength [11]. Grip strength has an important role in the softball game. The central aspect of hit speed and throwing velocity is the player's grip strength [11]. The technique does play a significant role in throwing movements. The efficiency force transmitted to the ball is judged by the ball's speed, distance, and direction after it is released. The thrown ball's speed and distance are directly related to the magnitude of the force used in throwing and the speed at which the ball is released. The joint action in the shoulder, elbow, wrist, and fingers contribute about $50 \%$ of the ball speed [12]. Each player position in softball is required to have good throwing and catching skills. The infielder must make a quick and accurate throwing motion [2] so that the resulting throw is in time, while the outfielder takes advantage of wind conditions to maximize velocity and distance [2].

Based on previous research, arm muscle strength and grip strength contribute to throwing skills in softball games. These two components contribute to the quality of the softball throwing. Several previous studies [9], [13], [14] have suggested that grip strength has a contribution to the speed of throwing. However, no data discusses the analysis of arm muscle strength and grip strength on the throw distance. The good throwing technique in softball if the resulting throw is fast, accurate, and covered. This can be supported by physical abilities, especially the upper body muscles' ability to support the underarm throwing and overhead throwing techniques in softball [14]. From the previous explanation, the overhead throwing technique has an important role in the softball game. The quality of the throw can have a significant effect on the game, especially when in a defensive position, both throwing accuracy, throw distance, and throwing speed. Therefore, this study aimed to determine the relationship between arm muscle strength and grip strength on the throwing distance.

\section{Method}

This research is a correlational study using a survey method. A total of 18 female softball athletes from Semarang City were involved in this study. The sampling technique used was total sampling. The data collection instruments used were tests and measurements that consisted of three tests, namely push-ups to measure the arm muscles' ability, a grip strength test using a handgrip dynamometer, and a softball throwing distance test [15]. The procedure of softball throwing distance test are: 1) sample assume a position in front of a restraining line 6 feet from the throwing line; 2) staying within these lines, sample is instructed to throw the softball as far as possible; 3 ) three trials are given; 4) the farthest of three trials is recorded to the nearest foot [15]. The procedure of grip strength test are: 1) the participants should be in a standing position, arms at their side, not touching their body; 2) keep elbow bent slightly; 3) participants squeeze the dynamometer with as much force as possible, being careful to squeeze only once for each measurement; 4) three trials should be made with a pause of about 10-20 seconds between each trial to avoid the effects of muscle fatigue; 5) record the result of each trial to the nearest pound or kilogram [16]. Data analysis used bivariate correlation analysis using SPSS 21. The 
correlation analysis result will consider the significance value 0.05 for data interpretation with the prerequisite test before analysis.

\section{Result and discussion}

Based on the data obtained, $33.33 \%$ of athletes have excellent arm muscle strength, $66.67 \%$ of athletes have good arm muscle strength, and no athletes have sufficient or less arm muscle strength.

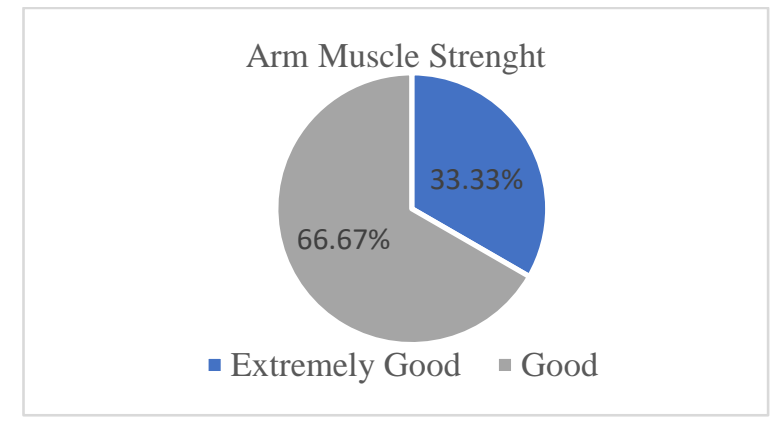

Fig. 1. Arm muscle strenght data of female softball athlet

Meanwhile, for grip strength, data obtained by $94.44 \%$ of athletes have sufficient grip strength, 5.56\% of athletes have insufficient grip strength, and no athlete has grip strength in the good and excellent categories.

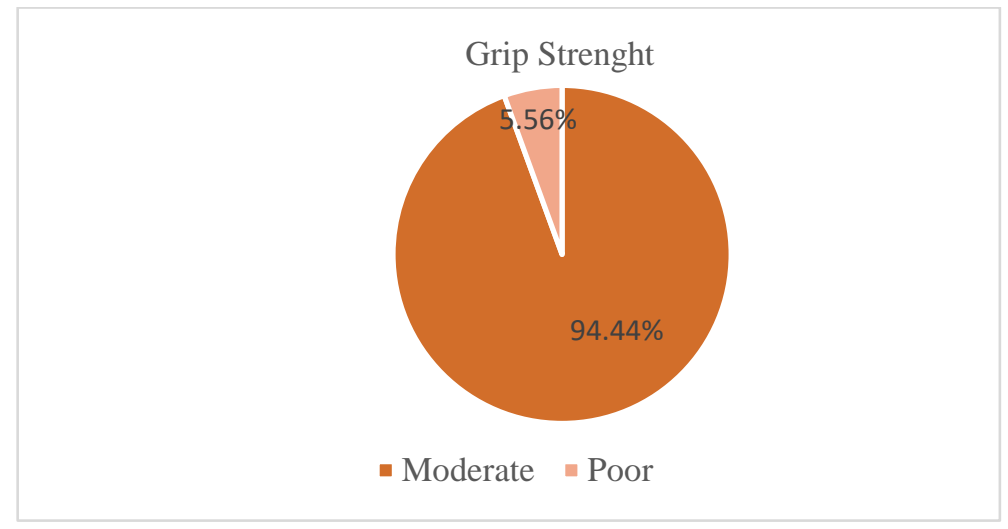

Fig. 2. Grip Strenght Data of Female Softball Athlete

Overhead throwing skills exert strong, repetitive force in the shoulder and elbow joints exposing the arms to a wide range of extreme movements [17]. Greater muscle strength is highly correlated with overall athlete performance [18]. Throwing skills play an important role in many sports such as baseball, softball, handball, basketball, and cricket. Although each sport has 
different throwing techniques, the muscles used in the throwing technique are the same. Physical and other factors impact the strength and accuracy of throws in a variety of sports and games. Therefore, a good throw is the result of good technique and the contribution of several physical factors [12].

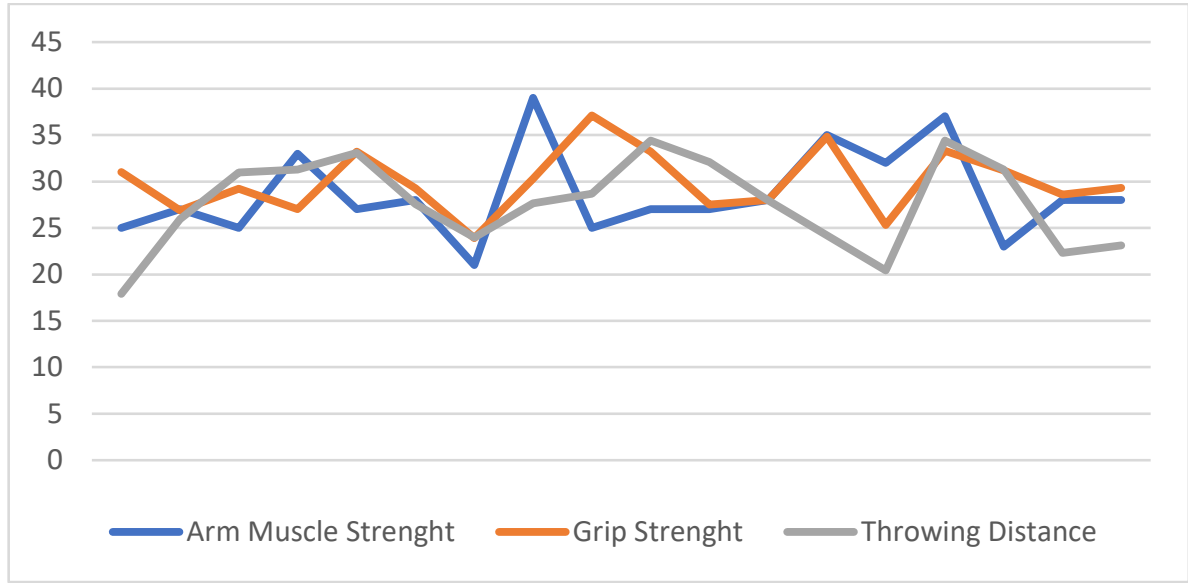

Fig. 3. Arm muscle strenght, grip strenght and throwing distance data

From the results of data analysis performed using correlation analysis, it was found that there was a significant relationship between arm muscle strength and throw distance in softball games with a correlation value of 0.893 and a significance level of 0.000 . Furthermore, the result shows no significant relationship between grip strength and throwing distance in softball, with a correlation value of 0.197 and a significance level of 0.448 (Table 1.).

A softball game is the development of a baseball game that requires physical abilities such as speed, strength, and endurance [11]. Besides, male softball players' throwing skills are associated with physiological parameters such as aerobic fitness, speed, explosive strength, flexibility, and grip strength of the right and left hands [9]. The research results were conducted to provide information that arm muscle strength contributes to the throwing distance. In contrast, grip strength does not have a significant relationship to the throwing distance. Arm muscle strength and grip strength are part of the components of physical condition required in softball games and contribute to throwing skills in softball games. Arm muscle strength is one component of the physical condition in softball. Arm muscle strength contributes to the skill of underarm throw, overhead throw, and side throw. Arm muscle strength in throwing techniques is useful for throwing accuracy, throwing speed, and throwing distance. Some of the proven benefits of increasing strength for cricketers are: 1) preventing injury 2) increasing bowling speed 3) increasing throw distance 4) reducing the effect of fatigue 5) increasing bat speed [19].

Table 1. The correlation result of arm muscle strenght, grip strenght and throwing distance

\begin{tabular}{|c|c|c|c|c|}
\hline & & $\begin{array}{l}\text { Arm Muscle } \\
\text { Strenght }\end{array}$ & Grip Strenght & $\begin{array}{l}\text { Throwing } \\
\text { Distance }\end{array}$ \\
\hline \multirow{3}{*}{$\begin{array}{l}\text { Arm Muscle } \\
\text { Strenght }\end{array}$} & Pearson & 1 & .169 & $.893^{* *}$ \\
\hline & Correlation & & & \\
\hline & Sig. (2-tailed) & & .517 & .000 \\
\hline
\end{tabular}




\begin{tabular}{llrrr}
\hline & $\mathrm{N}$ & 18 & 18 & 18 \\
\hline Grip Strenght & Pearson & .169 & 1 & .197 \\
& Correlation & & & .448 \\
& Sig. (2-tailed) & .517 & 18 & 18 \\
& $\mathrm{~N}$ & 18 & .197 & 1 \\
& Pearson & $.893^{* *}$ & & \\
Throwing & Correlation & & .448 & 17 \\
\hline Distance & Sig. (2-tailed) & .000 & 17 & \\
& $\mathrm{~N}$ & 17 & & \\
& & & & \\
& & &
\end{tabular}

Grip strength is one of the factors that affect the quality of throwing in softball games. Throwing skills in men's softball players are associated with physiological parameters such as aerobic fitness, speed, explosive strength, flexibility, and handgrip strength [9]. Grip strength is evaluated as a component of hand function in most sports. It is one of the best indicators of the overall strength of the limbs. Grip strength is an integrated muscle performance that can be generated in one muscle contraction [19], [20]. Based on the research findings, grip strength does not have a significant correlation with the throw distance. However, in previous studies, handgrip strength has a significant contribution to the speed of throwing. Speed of throwing the ball requires the ability to grip the ball to create control over the ball and increase ball spin, leading to an increase in throwing speed [21]. In addition, [22] has shown that the maximum handgrip strength is related to the speed of throwing the ball $(r=.79)$ [13]. Increasing grip strength is not only a skill associated with grasping an object. It can also increase the amount of force generated in a throw. Therefore, with the proper method to increase the hand's grip strength, it will help to analyze the effect of this force on the speed of the ball in throwing [23].

The limitation of this study is only focusing on measuring the throwing distance and does not measure other components of throwing skills such as throwing accuracy and throwing speed. To support the softball performance, throwing technique becomes important basic techniques to be learned and mastered.

\section{Conclussion}

There is a relationship between arm muscle strength and the throwing distance of the female softball athletes in Semarang city. There is no relationship between the grip strength and the throwing distance for female softball athletes in Semarang city. Arm muscle strength contributes to the throwing distance, while grip strength does not contribute to the throwing distance in female softball athletes in Semarang. For further research, it is necessary to study more variables related to throwing skills, including throwing accuracy and throwing speed.

\section{References}

[1] B. Suhartini, "Mengenal Olahraga Softball,” Yogyakarta, 2011.

[2] G. S. Roi and D. Bianchedi, "The science of fencing: Implications for performance and injury prevention," Sport. Med., vol. 38, no. 6, pp. 465-481, 2008.

[3] J. Nachtigal, M. Kim, K. Lee, T. Seidler, and M. Stocz, "Softball: Nothing Soft about It," J. Phys. Educ. Recreat. Danc., vol. 87, no. 9, pp. 36-41, 2016. 
[4] K. M. Singh and M. Singh, "RELATIONSHIP BETWEEN THE ANTHROPOMETRIC VARIABLES AND THROWING SKILL IN MALE SOFTBALL PLAYERS,” Eur. J. Phys. Educ. Sport Sci., vol. 3, no. 10, pp. 198-208, 2017.

[5] V. Aswathy, "The Relation between Hand Grip Strength with Hand-Anthropometric Variable in Inter-University Level Softball, Cricket and Hockey Players,” Int. J. Recent Sci. Res., vol. 9, no. 4(H), pp. 26068-26071, 2018.

[6] A. E. Saraya, S. Sugiyanto, and M. Doewes, "Anthropometric Factors And Physical Condition Dominant Determining Overhead Throws And Batting Skills In Softball," in The 4th International Seminar on Public Health Education (ISPHE 2018), 2018, vol. 12, no. Isphe, pp. 115-119.

[7] I. Mashudi, "Kontribusi konsentrasi, kekuatan otot lengan, kekuatan otot kaki, kelentukan punggung terhadap pukulan ke arah outfield olahraga softball," 2012.

[8] M. Alexander and C. Taylor, "Softball Throwing Fundamentals," 2012.

[9] K. M. Singh, "Association of physiological parameters with the throwing performance among the male softball players,” Int. J. Yogic, Hum. Mov. Sport. Sci., vol. 2, no. 5, pp. 602-605, 2017.

[10] D. Potter and L. Johnson, Softball: Step to Success. Champaign, IL: Human Kinetics, 2007.

[11] S. Koley and S. K. B, "THE RELATION BETWEEN HANDGRIP STRENGTH AND SELECTED HAND-ANTHROPOMETRIC VARIABLES IN INDIAN INTER-UNIVERSITY SOFTBALL PLAYERS $\square$," Phys. Educ. Sport, vol. 10, no. 1, pp. 13-21, 2012.

[12] D. S. Narwaria, "Effect of Distance and Position on Accuracy among Different Type of Throws," J. Tour. Hosp. Sport, vol. 4, pp. 13-20, 2015.

[13] R. A. Razak et al., "THE EFFECT OF HAND GRIP STRENGTH AND TRUNK ROTATION STRENGTH ON THROWING BALL VELOCITY," Movement, Heal. Exerc., vol. 7, no. 1, pp. 8998, 2018.

[14] K. M. Singh, "Relationship of physiological parameters with performance among softball players," Int. J. Acad. Res. Dev., vol. 2, no. 5, pp. 602-605, 2017.

[15] A. C. Lacy, Measurement \& Evaluation. San Fransisco: Pearson Education, Inc, 2011.

[16] Tufts, Brown, and Johns Hopkins, "Hand Grip Strength Protocol," 2003.

[17] A. Marquez-Lara, A. V. Stone, T. D. Luo, B. R. Parker, A. Sharma, and M. T. Freehill, "Top 50 cited journal articles on overhead throwing athletes: a bibliographic analysis,” JSES Open Access, vol. 1, no. 2 , pp. 55-62, 2017.

[18] T. J. Suchomel, S. Nimphius, and M. H. Stone, "The Importance of Muscular Strength in Athletic Performance," Sport. Med., vol. 46, no. 10, pp. 1419-1449, 2016.

[19] P. Sathya, V. Kadhiravan, K. S. Ramakrishnan, and T. M. Vedak, "Correlation between Hand Grip Strength and Shoulder Power in Cricket Players," Int. J. Sci. Res., vol. 5, no. 3, pp. 348-352, 2016.

[20] P. SATHYA, R. K. S, and S. K. V. V S. MAKESH BABU, "POWER WEB, RESISTIVE HAND EXERCISER AND HAND PUTTY EXERCISES FOR PINCH STRENGTH IN DENTAL PROFESSIONALS,” Int. J. Humanit. Arts, Med. Sci., vol. 2, no. 7, pp. 13-20, 2014.

[21] C. Ferragut, H. Villa, J. A. Abraldes, F. Argudo, N. Rodriguez, and P. E. Alcaraz, "Relationship among maximal grip, throwing velocity and anthropometric parameters in elite water polo players," J. Sports Med. Phys. Fitness, vol. 50, pp. 1-7, 2010.

[22] J. Shea, "The importance of grip strength," J. Strength Cond. Res., vol. 22, no. 1, pp. 112-118, 2007.

[23] A. B. Razak and K. Mea, "GENERAL RESISTANCE TRAINING , HAND GRIP STRENGTH TRAINING , AND TRUNK ROTATION STRENGTH TRAINING FOR OVERHEAD THROW IN," in 2nd International Conference on Physical Education, Health and Sport Science, 2013, pp. 16. 